\title{
From conference abstract to publication in the conservation science literature
}

Article

Accepted Version

Verde Arregoitia, L. and Gonzalez-Suarez, M. (2019) From conference abstract to publication in the conservation science literature. Conservation Biology, 33 (5). pp. 1164-1173. ISSN 1523-1739 doi: https://doi.org/10.1111/cobi.13296 Available at https://centaur.reading.ac.uk/81634/

It is advisable to refer to the publisher's version if you intend to cite from the work. See Guidance on citing.

To link to this article DOI: http://dx.doi.org/10.1111/cobi.13296

Publisher: Wiley

All outputs in CentAUR are protected by Intellectual Property Rights law, including copyright law. Copyright and IPR is retained by the creators or other copyright holders. Terms and conditions for use of this material are defined in the End User Agreement.

\section{www.reading.ac.uk/centaur}

\section{CentAUR}

Central Archive at the University of Reading

Reading's research outputs online 
1 Title: Going from conference abstract to publication in conservation science

\section{Article Impact Statement:}

3 Over half of all presentations at a major international conference on conservation science

4 ultimately became peer-reviewed publications.

5 Running head: Publication rates at the $25^{\text {th }}$ ICCB

6 Keywords: ICCB, posters, publication rates, scientometrics, transboundary

$7 \quad$ Word count: 5668

\section{Author addresses:}

9 Luis D. Verde Arregoitia -

10 Instituto de Ciencias Ambientales y Evolutivas, Universidad Austral de Chile, Campus Isla

11 Teja, Valdivia, Chile, 5090000

12 Manuela González-Suárez -

13 Ecology and Evolutionary Biology, School of Biological Sciences, University of Reading, 14 Whiteknights, Reading, RG6 6AS, UK

15 Corresponding author:

16 L.D. Verde Arregoita, email: luis@liomys.mx

\section{Acknowledgments}

We thank K. Wilson for comments on the initial outline for this work. Findings from this work were presented at the $28^{\text {th }}$ ICCB in July of 2017 by LDVA with the title: "A data-driven exploration of presentations at the $25^{\text {th }}$ ICCB: publication rates and presenter demographics". 
Every two years, the conservation community comes together at The Society for

Conservation Biology's International Congress for Conservation Biology (ICCB) to share new developments in conservation science and practice. Publication of content presented at conferences in scientific journals adds to a permanent record and helps increase its potential impact. However, quantitative research on publication rates for meetings relevant to conservation is lacking. We provide a data-driven exploration of the presentations at the $25^{\text {th }}$ ICCB held in Auckland, New Zealand in 2011. To study publication rates and presenter demographics, we recorded titles, number of authors, presenter affiliations, gender, country of study region, publication status, and the elapsed time between presentation and publication. Of the 980 contributions (782 talks and 198 posters), 587 (60\%) became publications. We found a mean time to publication of 13.7 months for all published abstracts, and 21.3 months when excluding abstracts published before the meeting. The gender breakdown of presenters was almost even (53\% male, $47 \%$ female), but the representation of the countries where the presenting authors were based at was biased. The political units with the most contributions were by far the USA, Australia, New Zealand, and the UK. Presenters based in English-speaking countries made up 74\% of the total sample, but this did not influence the likelihood of their abstract becoming a publication. Understanding the presentation to publication process in conservation is useful to identify biases and potential challenges that need to be addressed to make conference communications permanent and increase their reach beyond those in attendance. 
47 Since 1988, the Society for Conservation Biology's International Congress for Conservation Biology (ICCB) has brought together scientists, students, managers, policy-makers, writers, educators and other conservation professionals. ICCBs provide an opportunity for the conservation community to advance conservation science and disseminate research through a growing number of formats (talks, poster sessions, discussions, workshops, etc.). The ICCB is global in scope and attendees work for universities, government agencies, nongovernmental organizations, and private foundations.

Scientific conferences are an irreplaceable forum for discussing ideas, getting a sense of what the current state of research is, developing new research questions, and ultimately becoming a part of the conservation community. They serve as a major networking opportunity, and in the case of conservation conferences they bring together practitioners and academics who aspire to impact policies. In addition, conferences are a good outlet for presenting work at various stages of development (e.g., project outlines, preliminary results, finished and upcoming publications) and receiving immediate feedback. These presentations help increase the visibility of research and advocate for a field of interest in front of researchers from other disciplines as well as policy-makers. As an added benefit presenting can help develop the expertise needed to disseminate work in a clear and meaningful way, and to learn how to answer questions from others who may not be familiar with the topic. Presenting is also encouraged by many institutions which make funding for attending conferences conditional on the attendee also presenting (Rowe \& Ilic 2015).

These benefits of attending and presenting mean that a massive amount of content becomes available at conferences. Traditionally, information presented at conferences has been only available to those in attendance. However, there is great value in making conference 
communications permanent and increasing their reach, so that those who are unable to attend (because of family obligations, funding or time constraints, etc.) become aware of the presented material. New formats such as online conferences and recent practices of recording and sharing talks can contribute to achieve that goal. Conferences held on social media platforms such as Twitter have been successful in engaging large audiences (Avery-Gomm et al. 2016), in which the responses and facts shared by presenters could become a more permanent record even if unpublished. In addition, publication of the presented material can make the research presented at a conference accessible to the scientific community and in some cases, to the public in general. In this regard, refereed journals are still the foundation of scientific communications. Scholarly publishing broadens the research base of a discipline, and reflects individual or institutional research output, impact and productivity. By publishing our work, information is not lost and unnecessary replication can be avoided. Scholarly publications also include more detail and references, and they have the added rigour of peer-review (Scherer et al. 1994). However, not all research presented at conferences is eventually published.

As disciplines, bibliometrics and scientometrics track how knowledge develops and quantify the impact and productivity of scholars or institutions. This includes evaluating the content presented at conferences and the subsequent fates of the work presented. In a comprehensive review, Scherer et al. (2007) combined data from 79 separate reports of publication rates. These data represented 29,729 abstracts from $~ 250$ conferences in over 20 different disciplines (mostly biomedical). They found that $44.5 \%$ of conference communications were subsequently published in peer-reviewed journals, roughly 12 to 32 months after presentation, with oral presentations and those reporting 'positive' and 'significant' having higher publication rates. An earlier report (von Elm et al. 2003) found that abstracts were more likely to be published if presented either orally, at small meetings, or at meetings held 
in the USA. Information from medical and biomedical sciences is interesting, but these disciplines are very different from conservation biology, which affects the type of content presented at meetings, the nature of these meetings, and likely the resulting publication rates. Factors such as funding sources, professional affiliations with varying expectations to publish, and direct implications for human health make publication rate analyses for biomedical research incomparable with other fields.

At present, there is almost no research on publication rates that focuses on scientific meetings relevant to biological conservation. Bird and Bird (1999) analysed 425 abstracts presented at the 1989 and 1991 meetings for the Society for Marine Mammals, reporting that peerreviewed publications resulted from 55\% of presentations. McRoberts et al. (2014) examined presentations at annual meetings organized by The Wildlife Society between 1994 and 2006. Of 6,279 presentations, $28.2 \%$ resulted in publications. The mean time between presentation and publication was 30 months, and the authors determined that $87.9 \%$ of published communications came out after being presented at conferences and not before. We cannot be certain of how these figures compare with a conservation conference, since the proportion of conservation-themed presentations in these general biology and wildlife meetings was not reported. A separate analysis of 2527 conference abstracts from 11 meetings of the Mexican Society of Mammalogy between 1991-2012 (Briones-Salas et al. 2014) found that $14 \%$ of the presentations focused on mammal conservation. The study did not evaluate publication rates, but might provide an indication on the proportion of conservation research being presented at more general meetings. Nevertheless, the questions of: What are the publication rates for the major conservation biology conferences? and Which factors predict how presented content ultimately becomes part of the published knowledge base? remain unanswered. 
Our study is the first effort, to our knowledge, to address these questions, tracking the fates of studies presented at conservation conferences and exploring the factors influencing publication. We believe it would be useful to regularly quantify publication metrics and presenter demographics for an ICCB, a standard practice for many biomedical conferences. In this study we aimed to 1 ) determine the number of presentations given at the $25^{\text {th }}$ ICCB that are now published; 2) quantify the elapsed time between presentation and publication; 3) determine how different professional sectors contribute to presentation and publication metrics, and 4) identify topics related with publication or nonpublication of abstracts. This work provides baseline data for future analyses, and can help conference leadership and membership to evaluate several aspects of conference efficacy, and identify cohorts that may benefit from additional encouragement or help to publish their findings.

\section{Methods}

All data and computer code are available at

\section{https://anonymous.4open.science/repository/fa79ddb7-581f-4e0f-9b7d-3560a125b7a3/ .}

\section{Data collection}

The average 30-month (2.5 years) period between presentation and publication reported by McRoberts et al. (2014) provided us with a time frame for evaluating conference data as recent as 2012 without missing a considerable number of subsequent publications. This time frame corresponded with the 25th ICCB, held in Auckland in December of 2011 (which both authors attended). To collect data about this meeting, we used the physical and PDF abstract book in combination with the conference program website (http://www.birenheide.com/scb2011/schedule/; operational as recently as August 2018) to manually create a flat dataset capturing several properties relevant to each abstract (see Table 1). We examined every abstract in the program. 
We determined the gender of presenters using web searches for an online presence

(university or personal website, social media, academic search profiles) or general media coverage, or from having attended the presenter's talk or poster in person and previous personal experience in the conservation community. This approach makes assumptions about sex and gender, but we decided to use if for comparison with previous scientometric studies and other research on gender differences in authorship and publication patterns (e.g. Fox et al. 2016).

\section{Assessment of publication status}

We assessed the publication status for each abstract by searching first in general and academic search engines (Google, Bing, and Google Scholar), then by checking if the presenting author had some online presence (personal website, social media, university or lab profile, etc.) with a list of publications. The searches began with the first name initial or initials and the last name of the presenting author. If no corresponding publication list was found, we then searched for subsequent authors or keywords from the title.

For any potential matches, we compared the title, author list, research question, study area, methodology, sample sizes, and results between the abstract of the work presented at the meeting and the one for the publication. All publications with titles and abstracts that matched word for word with the conference abstract were automatically included. As a final check of eligibility, we considered that a published manuscript corresponded to full publication of a conference abstract when it met the following criteria: 1) at least one author on the abstract was listed as an author in the full publication, and 2) at least one assertive conclusion from the presented abstract was included in the conclusions of the publication. opinion pieces, and although we attempted to check for multiple articles arising from a single 
abstract, the abstracts rarely referred explicitly to specific cases (study sites, methods, conclusions) that would allow us to identify the associated publications. We recorded the earliest publication date given by a journal or book, often referring to electronic versions ahead of print.

Ancillary data

We collected secondary data that may have explanatory value. Most of this information was itself derived from the presenters' primary affiliation (i.e. the institution listed first in the case of multiple affiliations). We classified all the institutions into four categories: academic, government, NGO, and private. After recording the country in which the presenter's institution of primary affiliation is located, we determined if the presenter was based in a country in which English is the official language and the language of instruction for higher education, following the North Carolina State University graduate school's handbook (https://projects.ncsu.edu/grad/handbook/docs/official_language_english.htm). We provide the complete dataset as Supporting Information.

\section{Time to publication}

We used Kaplan-Meier estimators to analyze time to publication following Suñé et al. (2013).

These methods are commonly used in survival (time-to-event) analyses, in which the time until a particular outcome happens is of interest. We were interested in the time elapsed between the $25^{\text {th }}$ ICCB and until conference contributions appeared as publications. KaplanMeier analyses help us estimate a probability of survival (i.e. an abstract remaining unpublished) for hypothetical cohorts at each time interval and an overall survival function for the entire sample. We evaluated the influence of presenter demographics on publication times with log-rank tests, that tell us if two or more Kaplan-Meier curves fitted for different categories (e.g. men and women) are statistically equivalent, with the null hypothesis that 
there is no difference between them (Bradburn et al. 2003). To investigate the effect of several variables on the time it takes for a specified event to happen, we used a Cox regression model. This method estimates probability of the event of interest happening at a given time (the hazard), and the hazard ratios from these models quantify the effect of an independent variable on the hazard (Cox 1992).

In time-to-event analyses, the outcome of interest may not have occurred for all the subjects after the end of a study. The value used to define a period during which the outcome of interest did not happen is known as the censoring time. We set this value at 72 months, representing the time of the last thorough re-check of publication status for the abstracts. Abstracts reporting material published before the meeting were excluded from the survival analysis.

To evaluate if the number of authors listed on a presentation influenced publication probabilities, we discretised the number of authors (treated as categorical levels for which separate survival curves are fitted) into three balanced categories: sole authors, small teams (2-4 authors), and large teams ( $>4$ authors). We set these thresholds in the context of a largescale study (>20 million papers) of authorship in scientific papers (Aboukhalil 2014). As defined here: sole authors, small teams, and large teams are recognisable in the histogram of author numbers presented by Aboukhalil (2014). We ran all survival analyses using the $\mathrm{R}$ packages 'survival' (Therneau \& Grambsch 2013; Therneau 2015) and 'survminer' (Kassambara \& Kosinski 2018).

\section{Publication status}

We used recursive partitioning to relate the variables used in the survival analyses with the publication status of the abstracts. These methods split data into groups of increasingly similar observations based on the predictors and on how good the association between them 
214 is (Hothorn et al. 2006). We used multiple conditional inference trees (conditional random

215 forests) to estimate the relative importance of the explanatory variables in predicting

216 publication status, and a single-tree approach to display the partitioning of abstracts by

217 predictors. Given the exploratory nature of the analysis, we used the default settings on the

218 inference tree functions in the R package 'party' (Hothorn et al. 2006) to fit these models.

\section{Popular terms in presentation titles}

We used text analyses to quantify which were the most frequently used words or terms in presentation titles. We used the 'tidytext' (Silge \& Robinson 2016) package to extract textbased data into a format ready to be analyzed and parsed. To quantify the top terms, we split the titles into separate words or bigrams, and removed stop words (the most common short function words, such as: the, is, at, which, and on) using a custom list. We repeated this process for: all the titles, oral presentations, poster presentations, and published vs. unpublished contributions. Once we had identified the popular terms, we counted the number of titles (by format and publication status) that contained them. With a matrix of the word frequencies in the titles, we ran a hierarchical clustering analysis (Ward's method using Euclidean distances) to see if presentations would group together on the basis of their format or publication status.

\section{$231 \quad$ Results}

There was an almost even split between men (53\%) and women (47\%), roughly three quarters $(74 \%)$ of the presenters were based in English speaking countries, and most of the presenters were affiliated with academic institutions (73\%), followed by NGOs (13\%), government (9\%) and private institutions (5\%). 
Figure 1 shows where the presenters were based. The host country of New Zealand was well represented, but far behind the USA and Australia. The institution with the most presenters was the University of Queensland (Australia), followed by other universities and organizations in Australia and New Zealand (Table 3). Two NGOs (The Wildlife Conservation Society and The Nature Conservancy) also appeared in the list of top presenters, although the presenters affiliated to these organizations represented programs and venues in multiple countries.

\section{Publication rates}

The publication rate in peer reviewed journals or books was 60\% (587/980) for all abstracts, with similar rates for the different presentation formats. Proportionately, full length talks had the highest publication rate with $61 \%$ (406/660), followed by speed talks with $59 \%(72 / 122)$ and by posters with 55\% (108/198). Comparing publication rates of male and female presenting authors, female presenters had a higher publication rate of 63\% (292/460), while male presenters had a rate of 57\% (295/520). By type of primary institution, presenters with academic affiliations had the highest publication rate of $64 \%(455 / 715)$, followed by government scientists with 53\% (50/95), NGOs with 49\% (66/135) and finally private organizations with $46 \%$ (16/35). Of the sixty different themed sessions, the session with the highest publication rate was the Student Awards session (91\%). This is unsurprising, as the student presenters are more likely to be presenting completed studies from their thesis research in this competitive award session, and those participating had to submit extended abstracts that were used for selection prior to the conference.

\section{Time to publication}

Almost a quarter of published presentations (142 of 587) were published prior to the meeting. The abstract with the earliest publication date for its corresponding paper was published in 
July of 2008, and the abstract with the most recent publication date was published in October 2017. Considering all published presentations, the mean time between presentation and publication was 13.7 months. Considering only presentations that were published after the meeting, the mean time to publication was 21.3 months.

In the survival analysis, median time to publication (median survival time, or the time at which the survivorship function equals 0.5 ) was 49 months. This means that we can expect half of all the abstracts to become publications roughly four years after the conference. Comparing survival curves for talks vs. posters, by presenter gender, size of author team, and by the English-language status of the presenter institution's country, the difference (log-rank test) in median survival times was only significant for men vs. women presenters and for size of author teams (Table 2). Women published their work earlier than men (hazard ratio 1.26). Large teams published earliest (hazard ratio 2.44) compared with small teams (hazard ratio 2.12) and single authors, which we considered as the reference group (Fig. 2).

\section{Predictors of publication status}

We found that the number of co-authors in an abstract and the affiliation of the presenting author had the highest influence in determining publication status (Fig. 3). The single-tree model had better than random prediction accuracy $(0.63,95 \% \mathrm{CI}(0.61,0.67))$. The most important split in the conditional inference tree separated abstracts on the basis of team size: abstracts by presenters with no co-authors had the lowest predicted probability of publication (Fig. 3a). The next split separated abstracts by the primary affiliation of the presenting author, this split separated academic and non-academic (government, NGO, and private organizations) affiliations. Abstracts by presenters in academic institutions with at least one co-author were grouped in the largest terminal node, with a high predicted probability of publication. Abstracts by presenters in non-academic institutions had higher predicted 
probabilities of publication if more co-authors were involved. Presentation format, English

287 language status, and presenter gender had low importance values (i.e. excluding them did not decrease model accuracy) and were not included in the final model (Fig. 3b).

\section{Transboundary and in-country research}

290

291

292

We recorded the study area when there was one unambiguously reported in the abstract. This allowed us to visualize the amount of in-country research and the connections between the country of the presenters' institution and the country or countries of the study region.

Countries with more abstracts had more research happening within their borders and beyond them, and some countries such as India and Brazil were well-represented but exclusively by in-country research. The USA, UK and Australia had the most conservation research happening beyond their borders (Fig. 4). For visualization, we grouped countries using Wold Bank regions, which we modified to display Australia and New Zealand separately. For North America: $85 \%$ of cases correspond to the USA; and within Europe and Central Asia: the UK, France, and Sweden make up $60 \%$ of cases.

\section{Popular terms in presentation titles}

We found few overarching terms and themes in the abstract titles. Amongst the most popular terms: $251(25 \%)$ of all presentations contained the word 'conservation' in the title, 96 abstracts (10\%) mentioned 'species', 83 (9\%) included 'management' and 77 (7\%) biodiversity. 'Climate change' was also a recurring topic, present in 55 titles, of which 43 became publications. The most frequent terms varied by presentation format and publication status. For example: the term 'management' was rare in poster titles but popular in oral presentations, including several which became publications (Fig. 5a). The name of the host country appeared in English ("New Zealand") in 45 titles and in Māori (“Aotearoa") in just 3 titles. Hierarchical clustering on the matrix of word frequencies showed that poster titles 
310 clustered together and revealed differences between published and unpublished oral 311 presentations (Fig. 5b).

\section{Discussion}

313 We established baseline data on presenter demographics and summarized the fates of all 314 abstracts for the $25^{\text {th }}$ ICCB. Three quarters of presenters were affiliated with academic 315 institutions, and a similar proportion were based in English-speaking countries. This is 316 consistent with ICCBs being mainly academic conferences with English as the official 317 language. Regarding language we note that this particular ICCB was hosted by an Englishspeaking country, and it is possible this language prevalence may be less noticeable when ICCBs are hosted in other countries. We also found a relatively high publication rate, above the values reported for other disciplines (Scherer et al. 2007; McRoberts et al. 2014). Sixty percent of the presented abstracts are now peer-reviewed publications.

The 393 abstracts without a corresponding publication do not necessarily represent important science going unpublished. Instead, senior academics or practitioners might be summarizing various projects from the teams they lead or giving commentary on a trendy topic. This was evident in the text of some abstracts. In these cases, abstracts will not have corresponding publications identifiable by methods that depend on titles, author names, abstract text, and key words. For example, these kinds of abstracts included: a presentation describing the goals and history of the PAMPA project (wwz.ifremer.fr) of Marine Protected Areas, commentary on an expert's personal involvement in local conservation initiatives in Australia, or a summary of the success of various community management programs for wildlife in Mexico. It is not straightforward to define which abstracts addressed 'broad' topics, yet we noted that 63 presentations had overviews, summaries, or commentary as their stated objectives. Only three of these became publications. 
334 Additionally, some attendees may be publishing their work in other languages that are usually excluded from bibliometric analyses. In this study, we noticed (but did not consider in the analysis) several likely publications in Spanish, French, Chinese, Finnish, and Portuguese. This relates to the findings of Amano et al. (2016), where almost $36 \%$ of scientific articles on biodiversity conservation published in 2014 were not published in English. Finally, conservation conferences feature presenters from NGOs, private foundations, civilian groups, and government entities. McRoberts et al. (2014) noted that academic publishing may not be a work requirement for non-academic presenters, who sometimes report their research internally without a corresponding publication. This may be the reason for non-publication in some cases. However, we only considered the presenting authors and their primary affiliation, so we may have underestimated the academic ties of non-academic presenters (by our definition) and their collaborators.

Publication was more likely and faster in studies with more co-authors and from academic institutions (of the presenting author). These effects may reflect the known benefits of collaboration in increasing the quality and rigor of a study and the higher accountability and incentive to publish (Cheruvelil et al. 2014) as well as the importance of publications in academia. On the contrary, we found little to no influence of presenter gender and language (based on institution country) on the fates of the abstracts. These are welcome news which may reflect the successful efforts from The Society of Conservation Biology and its members to increase representation and publication of traditionally underrepresented groups. We also found that poster and podium presentations had similar publication rates and overall times to publication. Posters are often represented as an opportunity for students and junior researchers for scrutiny, feedback, and interaction with peers (Withers 2012), but a format for which publication may be less likely. However, there is no evidence showing that poster presentations are a less demanding format or limited to early career researchers (Rowe \& Ilic 
2015). Interestingly, our exploration of text titles revealed that podium presentations and posters may be tackling different study themes and topics within conservation. Thus, posters present research of good quality (likely to lead to publications) but on different topics. This calls for better appreciation of poster presentations within the range of scientific communications by both conference attendees and organizers.

The geographic component of our results reflects known biases in conservation research (Lawler et al. 2006), determined by geopolitical, historical and linguistic relationships between countries, scientific investment related to wealth, and to some extent by the conservation situation of tropical regions with high biodiversity and large numbers of threatened taxa (Meijaard et al. 2015). This includes the differences in research effort, represented by the countries where the presenters' institutions were based in relation to their study sites. We found similar patterns to Di Marco et al. (2017), who report that $40 \%$ of conservation studies published 2011-2015 were from the USA, Australia or the UK. We found that directionality in transboundary research was extremely lopsided. Multiple abstracts by presenters based in the USA, UK, and Australia reported research on sites and study taxa in Africa and Latin America, while no presenters based in Africa or Latin America presented work on conservation science in the USA, Western Europe, or Australia. Despite the distance and associated travel costs, the country with the most presenters was the United States of America, followed by other English-speaking countries like Australia and England, all with strong scientific traditions and well- funded institutions (Wilson et al. 2016). It would be interesting to see if this pattern changes for subsequent ICCBs, particularly those hosted in developing economies such as the latest edition held in Colombia and the upcoming edition scheduled to take place in Malaysia. 
We found high publication rates, compared to other disciplines, which reflect favourably on ICCB and its organizers. Because most scientific journals expect novelty in the work they accept for publication, these high publication rates can help refute recent criticism (Kircherr \& Biswas 2017) on how academic conferences are failing to deliver novel content despite their increasing costs and environmental footprints (Fraser et al. 2017). However, we note that we analyzed a single conference. In contrast, publication rates for clinical urology meetings have been painstakingly evaluated six times between 2004 and 2017 (Moon \& Harding 2017), and comparisons across multiple clinical disciplines are common (Oliver et al. 2003). Gathering long-term data would be valuable to further improve the way conservation conferences are organized and documented, and help define appropriate incentives for presenting and publishing. The latest iteration of ICCB (28th ICCB in Cartagena, Colombia, July 2017) implemented incentives in the form of a new publishing opportunity, to feature the best research presented at the meeting in special issues of the SCB affiliated journals, with a submission deadline set approximately three months after the meeting. The organizers also encouraged presenters to upload their posters and presentation slides to a free and open access hosting platform. Future bibliometric and scientometric analyses would be useful to evaluate the impact of these activities, which we expect would be beneficial.

Our analyses offer valuable information but there were some factors we could not consider. First, with our approach based on open-source web information we could not determine the professional status of presenters, but professional status (recorded and provided by a regulatory body) has been found to strongly influence publication rates for veterinary ophthalmology conferences (Ofri et al. 2017). Different career situations vary in funding levels, incentives or pressure to publish, as well as on experience navigating the publication process. Organizers of conservation conferences could create a dataset of presenter-provided 
information on career status, and also poll presenters on whether or not the work they are presenting is published, submitted, or even intended for publication. This would need to be optional and compliant with ethics and data privacy regulations, but would provide a very valuable resource to assess the presentation to publication pathway. A second factor we could not consider is that ultimately, publishing is in the hands of the authors who may simply choose not to write and submit their work. Contacting individual presenters is a potential way to evaluate reasons for not publishing work. A review by Scherer et al. (2015) found that 'lack of time' and 'issues with coauthors' were the most common responses given by presenters of biomedical conferences who had not published their work. We expect these reasons would be also common among presenters of conservation conferences, but future work would be necessary to determine why conservation research presented at conferences is not published.

Overall, our exploration of presenter demographics and publication rates provides important baseline data which we hope will help The Society for Conservation Biology and the conservation community in general to understand and address gaps and biases in the types of institution and geographic representation of presenters at future meetings. We were happy to see high publication rates and gender equality but we would like to end this text with three recommendations for further improvement:

1. Current challenges in biodiversity conservation need input and participation from many different voices and expertise from different backgrounds, geographies, and disciplines. The Society for Conservation Biology and organizing ICCBs committees should continue their successful approach to encourage gender equity and participation from a diverse community, but we recommend providing additional support for presenters from nonEnglish speaking countries. 
431

432

433

434

435

436

437

438

439

2. To facilitate future scientometric analyses the ICCBs should consider implementing a way to gather and analyze presenter-provided information on career status, presentationto-publication plans, and additional data that can help us better understand how conservation science is disseminated. An online form could also be available after the conference to allow authors to post publication notices and updates on their work.

3. The Society for Conservation Biology should continue to promote publication of work presented at ICCBs, for example via special issues, but also considering the use of alternative formats that may be more appealing to non-academics. 
441 abstracts.csv - Abstract data collected from the conference program plus derived secondary 442 data for each abstract, in comma-separated format.

\section{Literature Cited}

444

Aboukhalil R. 2014. The rising trend in authorship. The Winnower.

Avery-Gomm S, Hammer S, Humphries G. 2016. The age of the Twitter conference. Science 352:1404-1405.

Bird J, Bird M. 1999. Do peer-reviewed journal papers result from meeting abstracts of the Biennial Conference on the Biology of Marine Mammals? Scientometrics 46:287297.

Bradburn MJ, Clark TG, Love SB, Altman DG. 2003. Survival Analysis Part II: Multivariate data analysis - an introduction to concepts and methods. British Journal Of Cancer 89:431.

Briones-Salas M, Ramos D, Santiago Y. 2014. Análisis de los trabajos presentados en los Congresos Nacionales organizados por la Asociación Mexicana de Mastozoología (AMMAC). Therya 5:461-480.

Cheruvelil KS, Soranno PA, Weathers KC, Hanson PC, Goring SJ, Filstrup CT, Read EK. 2014. Creating and maintaining high- performing collaborative research teams: the importance of diversity and interpersonal skills. Frontiers in Ecology and the Environment 12:31-38.

Cox DR. 1992. Regression models and life-tables. Pages 527-541. Breakthroughs in statistics. Springer.

Di Marco M, et al. 2017. Changing trends and persisting biases in three decades of conservation science. Global Ecology and Conservation 10:32-42.

Fraser H, Soanes K, Jones SA, Jones CS, Malishev M. 2017. The value of virtual conferencing for ecology and conservation. Conservation Biology 31:540-546.

Hothorn T, Hornik K, Zeileis A. 2006. Unbiased Recursive Partitioning: A Conditional Inference Framework. Journal of Computational and Graphical Statistics 15:651-674. 
Kassambara A, Kosinski M. 2018. Survminer: drawing survival curves using 'ggplot2'R package version 0.4.3.

Kircherr J, Biswas A. 2017. Expensive academic conferences give us old ideas and no new faces. The Guardian, 30 Aug 2017.

Lawler JJ, et al. 2006. Conservation science: a 20-year report card. Frontiers in Ecology and the Environment 4:473-480.

McRoberts JT, Ferguson AW, Schwalm DL, Timmer JM, Ballard WB. 2014. Publication rates of presentations given at annual conferences of The Wildlife Society, 19942006. Wildlife Society Bulletin 38:134-141.

Meijaard E, Cardillo M, Meijaard EM, Possingham HP. 2015. Geographic bias in citation rates of conservation research. Conservation Biology 29:920-925.

Moon A, Harding C. 2017. Publication rate of abstracts presented at the British Association of Urological Surgeons Annual Meeting-10 years on. Journal of Clinical Urology 10:22-27.

Ofri R, Bdolah-Abram T, Yair N. 2017. Factors affecting peer-reviewed publication of abstracts presented at meetings of the European College of Veterinary Ophthalmologists (2008-2012). Veterinary Ophthalmology 20:533-538.

Oliver DW, Whitaker IS, Chohan DPK. 2003. Publication rates for abstracts presented at the British Association of Plastic Surgeons meetings: how do we compare with other specialties? British Journal of Plastic Surgery 56:158-160.

Rowe N, Ilic D. 2015. Rethinking poster presentations at large-scale scientific meetings - is it time for the format to evolve? The FEBS Journal 282:3661-3668.

Scherer RW, Langenberg P, von Elm E. 2007. Full publication of results initially presented in abstracts. Cochrane Database of Systematic Reviews.

Scherer RW, Ugarte-Gil C, Schmucker C, Meerpohl JJ. 2015. Authors report lack of time as main reason for unpublished research presented at biomedical conferences: a systematic review. Journal of Clinical Epidemiology 68:803-810.

Silge J, Robinson D. 2016. tidytext: Text mining and analysis using tidy data principles in r. The Journal of Open Source Software 1:37.

Suñé P, Suñé JM, Montoro JB. 2013. Positive Outcomes Influence the Rate and Time to Publication, but Not the Impact Factor of Publications of Clinical Trial Results. PLOS ONE 8: 54583.

Therneau TM. 2015. A package for survival analysis in S. 2015. Version 2.38. 
501 Therneau TM, Grambsch PM 2013. Modeling survival data: extending the Cox model. Springer Science \& Business Media. von Elm E, Costanza MC, Walder B, Tramèr MR. 2003. More insight into the fate of biomedical meeting abstracts: a systematic review. BMC Medical Research Methodology 3:12.

506 Wilson KA, Auerbach NA, Sam K, Magini AG, Moss ASL, Langhans SD, Budiharta S, 507 Terzano D, Meijaard E. 2016. Conservation Research Is Not Happening Where It Is Most Needed. PLOS Biology 14:e1002413.

510 
512 Table 1. Description of the data collected from ICCB abstracts reflecting oral and poster

513 presentations.

Field

Name of the presenting author

Presentation title

Primary institution of affiliation for the presenting author

Number of coauthors

Presenting author gender

Author country

Study country (when applicable)

Published

Talk or Poster

Publication date

Session
Notes

Highlighted in the abstract book

Copied verbatim

In case of multiple affiliations, first listed Integer $\mathrm{M}$ or $\mathrm{F}$

Country where the author's institution is located

Country or countries where the study focused on

TRUE or FALSE

Presentation format

Month \& Year

Session name

515 Table 2. Variables tested using time-to-event analysis.

\begin{tabular}{lll} 
Variable & Levels & Logrank test \\
\hline Presentation format & Poster, Talk & $1.7(\mathrm{p}=0.2)$ \\
Presenting author gender & Men, Women & $5.6(p=0.02)$ \\
Size of author team & $1,2-4,>4$ & $35(p<0.001)$ \\
$\begin{array}{l}\text { English Language status in } \\
\text { presenters' country }\end{array}$ & English as official language, & $1 \quad(\mathrm{p}=0.3)$ \\
& Other &
\end{tabular}


517 Table 3. Institutions with $>9$ presentations, based on the primary affiliation of the presenting

518 author.

\begin{tabular}{lll} 
Institution & Country/Location & Presentations \\
\hline University of Queensland & Australia & 30 \\
Wildlife Conservation Society & multiple & 26 \\
James Cook University & Australia & 25 \\
Victoria University of Wellington & New Zealand & 21 \\
University of Otago & New Zealand & 19 \\
University of Melbourne & Australia & 18 \\
Landcare Research & New Zealand & 16 \\
The Nature Conservancy & multiple & 16 \\
University of Adelaide & Australia & 16 \\
Imperial College London & United Kingdom & 15 \\
University of Auckland & New Zealand & 14 \\
University of Canterbury & New Zealand & 11 \\
Massey University & New Zealand & 10 \\
University of California Berkeley & USA & 10 \\
&
\end{tabular}




\section{Figure Legends}

523 Figure 1. Number of contributions by country to the $25^{\text {th }}$ ICCB based on locations of the

524 listed primary institution of each presenting author.

525 Figure 2. Survival plots showing the proportion of unpublished work separating: (a)

526 presenters of each gender, and (b) different team sizes (number of coauthors discretised into

527 three categories). Vertical dashed lines show median survival times for curves that crossed

528 the 0.5 threshold.

529 Figure 3. Results of the recursive partitioning model explaining publication status of work 530 presented at $25^{\text {th }}$ ICCB.

531 Figure 4. Circular plot of transboundary and in-country research presented in the $25^{\text {th }}$ ICCB

532 for abstracts with geographic context (706 of 980). Arrows at the end of cords show

533 directionality, tick marks show number of cases.

534 Figure 5. Presentation terminology. a) The 15 most common terms for each presentation

535 format and publication status, arranged to show similarities and differences. Term

536 frequencies were calculated relative to the number of presentations by format and scaled for

537 visualization. b) Hierarchical clustering dendrogram showing pair-wise dissimilarity between

538 titles by format and publication status in terms of word frequencies. 


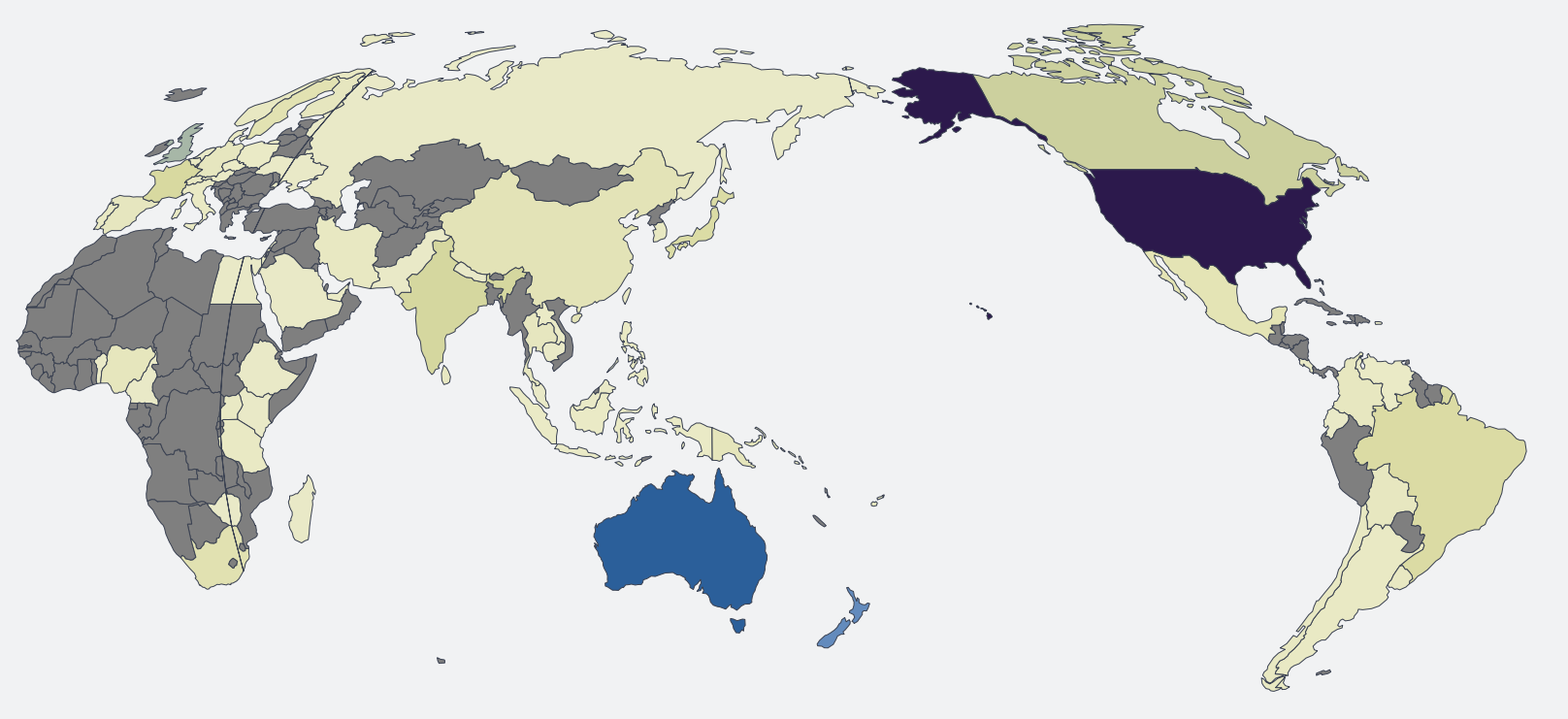

Number of contributions 


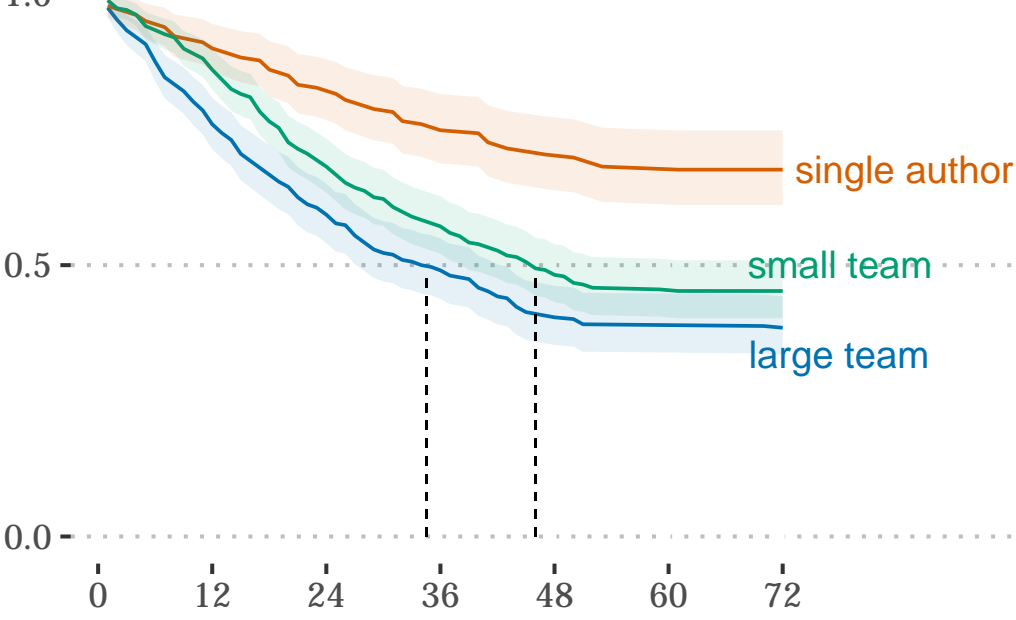


team size $(\mathrm{n}=980)$

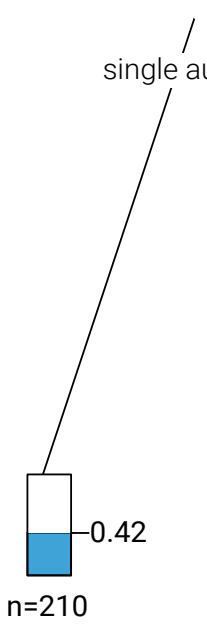

a) e author

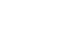$$
\text { 11 }
$$

large team, small team

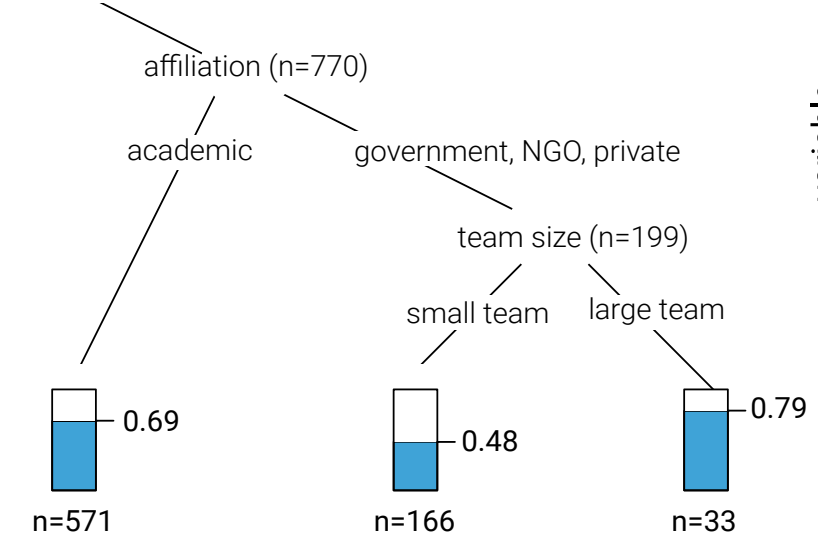

b)

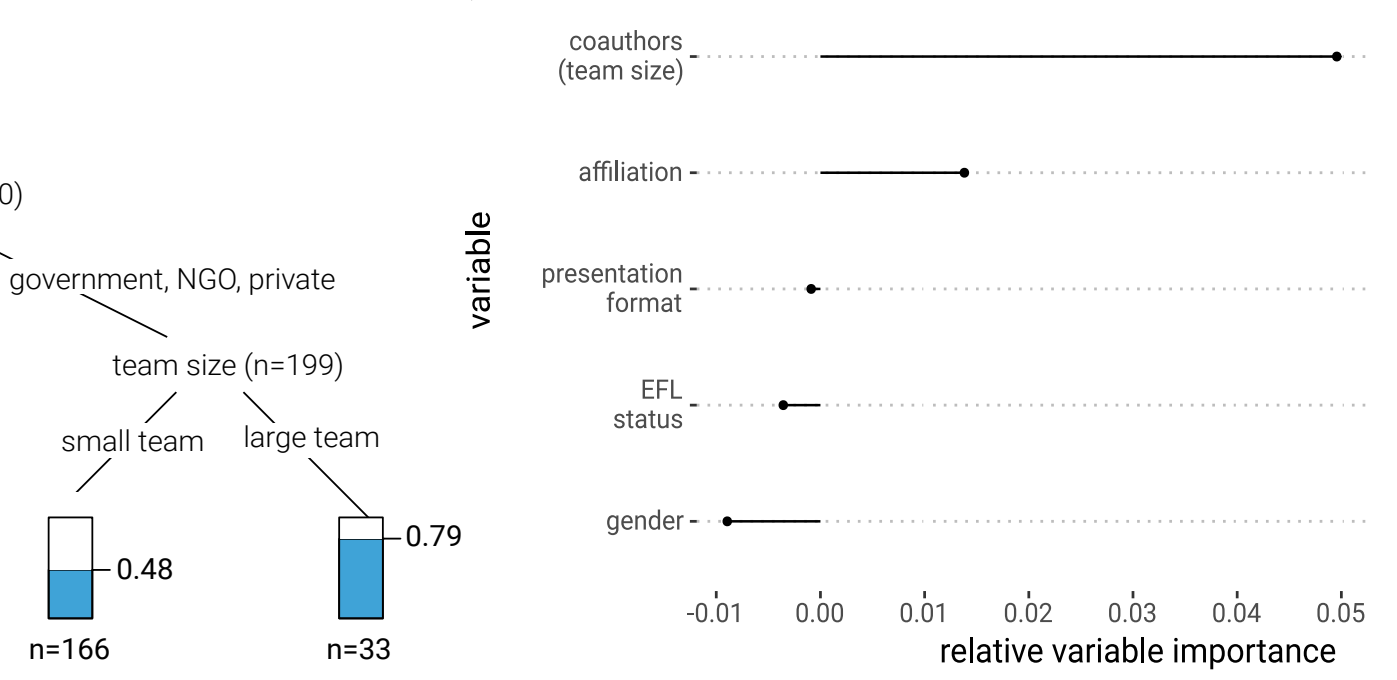




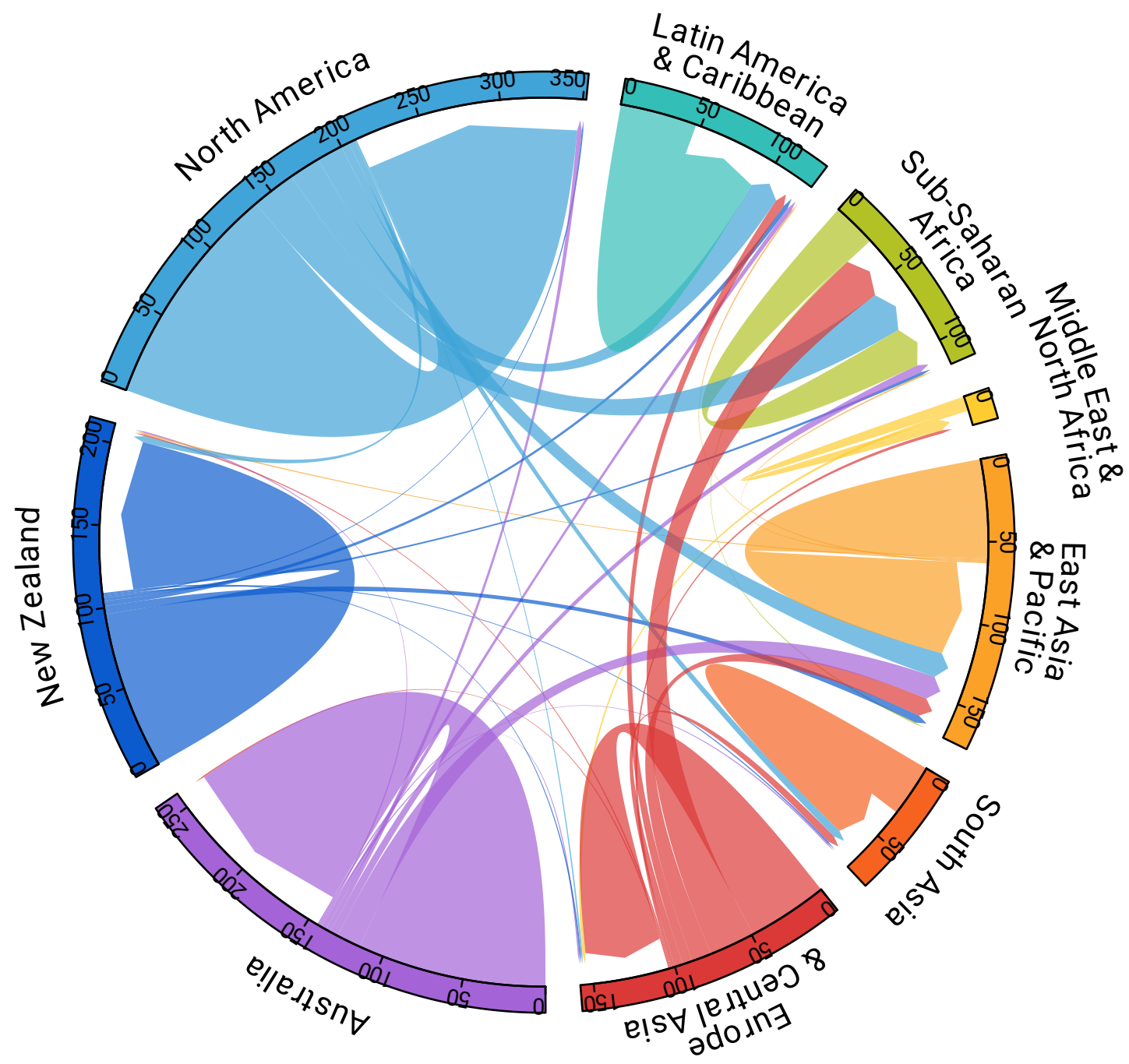


a)

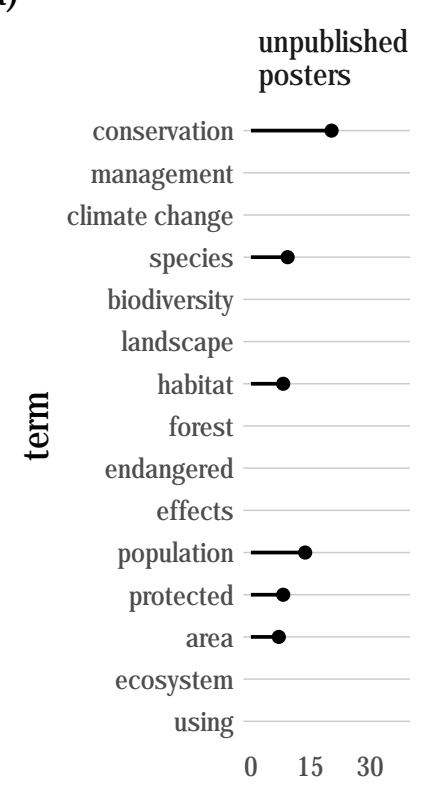

\section{published}

posters
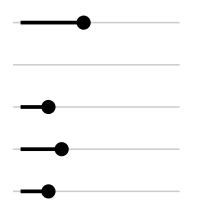

$\rightarrow$

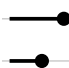

$\rightarrow$

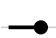

$\rightarrow$
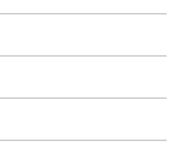

$0 \quad 15 \quad 30$

relative frequency (scaled)

b)

unpublished published

talks
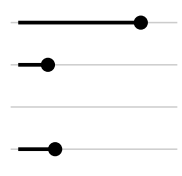

$\rightarrow$

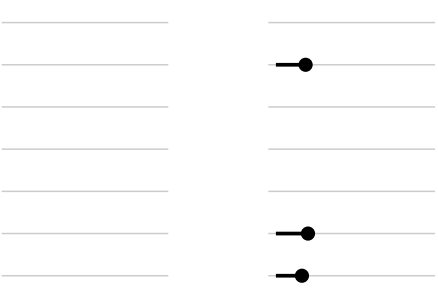

$\rightarrow$

$\begin{array}{lll}0 & 15 & 30\end{array}$
- unpublished posters

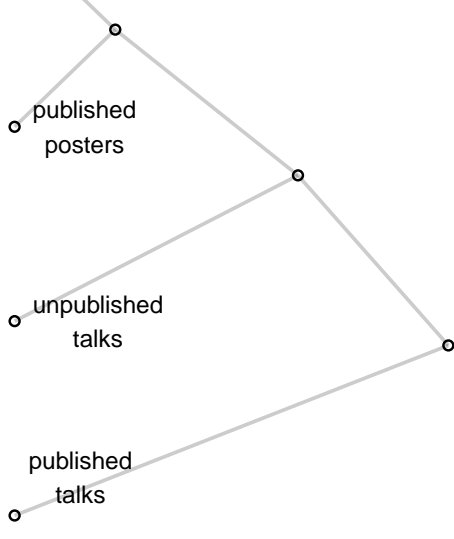

